\section{In Vivo Influx of Free and Esterified Plasma Cholesterol into Human Aortic Tissue without Atherosclerotic Lesions}

\author{
Steen Stender and Erik Hjelms \\ Department of Clinical Chemistry and Department of \\ Thoracic Surgery, Rigshospitalet, \\ University Hospital, Copenhagen, Denmark
}

A influx of plasma cholesterol into human aortic intimamedia tissue, specimens of the ascending aortic wall without visible atherosclerosis were obtained from patients undergoing aortic valve replacement. Before the operation the patients were intravenously injected with autologous plasma in which the lipoproteins were labeled with radioactive cholesterol. The influence of the duration of the exposure time (0.3-114 h) and of the distribution of radioactivity between free and esterified cholesterol in plasma on the amount of radioactivity found in the arterial wall was studied by the simultaneous use of ${ }^{3} \mathrm{H}$ and ${ }^{14} \mathrm{C}$-cholesterol. It was shown that the influx of free and esterified cholesterol into the intima-media layer of the tissue could be calculated from a set of linear equations that relate the labeled sterols in the tissue to the average specific activities in plasma. In nine patients between 50 and $70 \mathrm{yr}$ of age with $4.2-5.9 \mathrm{mM}$ total cholesterol in plasma, the influx of free cholesterol and of esterified cholesterol was 1.2-8.8 and 1.0-12.5 nmol $\times \mathrm{cm}^{-2} \times \mathrm{d}^{-1}$, respectively. Both hydrolysis and esterification of the sterol fractions in the aortic tissue and exchange of free cholesterol between the plasma lipoproteins and the tissue were demonstrated. The cholesterol content of the intima-media layer was $0.6-2.3 \mu \mathrm{mol}$ $\times \mathrm{cm}^{-2}$. This corresponds to the influx of esterified cholesterol during a period of only $0.1-3.5 \mathrm{yr}$, which is short compared with the lifespan of the patient. Our data thus suggest that removal of esterified cholesterol from aortic tissue without visible atherosclerosis repre-

Received for publication 5 January 1984 and in revised form 29 June 1984.

J. Clin. Invest.

(C) The American Society for Clinical Investigation, Inc.

$0021-9738 / 84 / 11 / 1871 / 11 \quad \$ 1.00$

Volume 74, November 1984, 1871-1881 sents a major importance for the cholesterol concentration in the tissue.

\section{Introduction}

Free and esterified cholesterol are major constituents of the atherosclerotic lesion in human arteries. The in vivo transfer of free and esterified cholesterol from plasma lipoproteins into the arterial wall of humans are therefore important to an understanding of the pathophysiology of atherosclerosis. This transfer process has been studied by only a few investigators, who administered labeled cholesterol orally or intravenously to patients (1-3). Arterial specimens were obtained days or months later when the patients died or underwent arterial surgery (4). The cholesterol influx was calculated on the basis of labeled cholesterol in the tissue and the specific activity in plasma. Due to a possible efflux of labeled cholesterol from the arterial tissue, this calculation results in a minimum value. Furthermore, this influx may reflect only free cholesterol exchange between the intimal surface and the surface of the plasma lipoproteins, as it occurs between plasma lipoproteins and red blood cells (5). The exchange process may be of minor biological importance, because it can take place without a net transfer (6).

The in vivo influx of esterified cholesterol into human arteries has never previously been determined (4). Moreover, it is not known if human arterial tissue under in vivo conditions hydrolyzes esterified cholesterol and esterifies free cholesterol, although the necessary enzymatic activities have been found in the tissue (7).

In the present study we have established a time frame for influx measurements based on the in vivo uptake of labeled plasma cholesterol by the aortic intima-media. The uptake period should be long enough to minimize the significance of labeled cholesterol in contaminating plasma left on the tissue after its removal from the aorta and short enough to minimize the significance of a possible efflux of labeled cholesterol from the aortic intima-media in situ. During this period we measure the influx of free and esterified cholesterol into human aortic tissue by a technique which takes into account the possibility that the arterial wall may hydrolyze esterified cholesterol and 
esterify free cholesterol subsequent to its entrance from plasma. This technique has previously been used in hypercholesterolemic rabbits $(8,9)$.

\section{Methods}

Patients and study protocol. Patients with a dilatation of the ascending aorta who were scheduled for aortic valve replacement either due to stenosis or insufficiency of the aortic valve were studied. Plasma samples were obtained from the patients 4-7 $\mathrm{d}$ before the operation. The plasma was labeled with ${ }^{3} \mathrm{H}$ - and ${ }^{14} \mathrm{C}$-cholesterol and reinjected 0.3-114 $\mathrm{h}$ before the operation. Blood samples were drawn 2-3 times a day. At the operation a piece of tissue was excised from the ascending aorta.

Informed consent was given by all of the patients after explanation of the investigation's purpose and protocol. It was stressed that the patients would not obtain any therapeutic benefit from the investigation. The amount of ${ }^{3} \mathrm{H}$ and ${ }^{14} \mathrm{C}$-cholesterol, $\sim 100 \mu \mathrm{Ci}$ and $30 \mu \mathrm{Ci}$, respectively, which were injected intravenously and the procedure for preparation of a sterile injectate was approved by the appropriate Danish Health Authorities.

Isotope purity. We obtained $1 \alpha, 2 \alpha(\mathrm{n})-{ }^{3} \mathrm{H}$-cholesterol and $4-{ }^{14} \mathrm{C}-$ cholesterol from Amersham International (Buckinghamshire, England). Before use we determined the purity by chromatography on precoated thin-layer chromatography (TLC) ${ }^{1}$ plates (silica gel 60 , E. Merck, Darmstadt, Federal Republic of Germany) in a hexane/diethyl ether/ glacial acetic acid 50:50:1 ( $\mathrm{vol} / \mathrm{vol})$ solvent system. The radioactive cholesterol was used only if $>95 \%$ of the labeled sterol co-migrated with a cholesterol standard (C-8258, Sigma Chemical Co., St. Louis, MO).

Experimental procedures. $60 \mathrm{ml}$ of blood was drawn from the patient into a sterile syringe that contained $6 \mathrm{ml}$ anticoagulant (Fenwal CDP blood pack, Travenol Laboratories S.A., Castlebar, Eire, Ireland). Plasma was separated by centrifugation and subsequently filtered through a $0.22-\mu \mathrm{m}$ millipore filter (Millex-GS, Millipore S.A., Molsheim, France) into two rubber-sealed sterile glass vials. About $0.5 \mu \mathrm{mol}{ }^{14} \mathrm{C}$ cholesterol $(30 \mu \mathrm{Ci})$ dissolved in $0.2 \mathrm{ml}$ ethanol was injected into one vial containing $10-15-\mathrm{ml}$ of the plasma. The vial was subsequently incubated at $37^{\circ} \mathrm{C}$ for $40-48 \mathrm{~h}$. About $0.004 \mu \mathrm{mol}{ }^{3} \mathrm{H}$-cholesterol $(150$ $\mu \mathrm{Ci})$ dissolved in $0.2 \mathrm{ml}$ ethanol was injected into the second vial containing $10-15 \mathrm{ml}$ of the plasma. This vial was also incubated for the same period at $37^{\circ} \mathrm{C}$ for incorporation of the label into esterified cholesterol, or at $4^{\circ} \mathrm{C}$ when only free cholesterol in the plasma was to be labeled. The plasma was filtered twice through $0.22-\mu \mathrm{m}$ filter before it was injected intravenously into the patients.

Some patients were injected intravenously with the cholesterollabeled plasma preparation during the operation, i.e., $0.2-0.7 \mathrm{~h}$ before the aortic tissue specimen was removed. This was done in order to estimate the amounts of contaminating plasma on the aortic tissue. Other patients were injected first with a ${ }^{14} \mathrm{C}$-labeled preparation, which had incubated for $40 \mathrm{~h}$ at $37^{\circ} \mathrm{C}$, and then $40-48 \mathrm{~h}$ later injected again, but this time with a ${ }^{3} \mathrm{H}$-labeled preparation, which also had incubated for $40 \mathrm{~h}$ at $37^{\circ} \mathrm{C}$. In that way it was possible in the same patient to investigate to what extent the amount of radioactivity found in the aortic tissue was affected by the duration of the uptake period, i.e., the

1. Abbreviations used in this paper: HDL, high density lipoproteins ( $d$ $>1.063)$; LDL, low density lipoproteins $(1.019<d<1.063)$; VLDL, very low density lipoproteins $(d<1.019) ; K_{\mathrm{E}}$, influx of esterified cholesterol; $K_{F}$, influx of free cholesterol; TLC, thin-layer chromatography. time from injection of the labeled lipoproteins until the tissue was removed.

Still other patients were injected with a mixture of the ${ }^{3} \mathrm{H}$ - and ${ }^{14} \mathrm{C}$-labeled preparations. The ${ }^{14} \mathrm{C}$ was present mainly in esterified cholesterol and ${ }^{3} \mathrm{H}$ mainly in free cholesterol or vice versa. In that way it was possible to investigate in the same patient to what extent the amounts of labeled free and esterified cholesterol in the aortic tissue were affected by a difference in the specific activity between free and esterified cholesterol in plasma. Blood samples were collected in EDTA-containing tubes from the patients from the time of injection until the tissue was removed. The plasma was immediately separated from the red cells. One plasma aliquot was frozen, while another was kept at $4^{\circ} \mathrm{C}$ for up to $24 \mathrm{~h}$ before ultracentrifugation.

After a patient was connected to the heart-lung machine, a hockeystick-shaped piece of tissue was excised from the anterior wall of the ascending aorta $2-3 \mathrm{~cm}$ above the aortic valve. This was done in order to normalize the aortic diameter postoperatively. The tissue was immediately rinsed in $4^{\circ} \mathrm{C}$ saline. The area was outlined and the tissue separated into 4-5 layers by use of two pairs of forceps.

Analytical procedures. Plasma samples were adjusted to $d=1.019$ and $d=1.063$, respectively, and centrifuged at $4^{\circ} \mathrm{C}$ at $1.58 \times 10^{8} \mathrm{~g}$ $\mathrm{min}$ in a 40.3 Beckman rotor. The top and bottom fractions were separated by tube slicing. Aliquots of whole plasma and of the various ultracentrifuged fractions were adjusted to $73 \%$ ethanol. After addition of hexane and water, the lipids were partitioned between the hexane and aqueous alcohol phases (10). Aliquots of the hexane phase were used for determination of total cholesterol radioactivity and for separation of free and esterified cholesterol by TLC (11). Lipids were extracted from silica gel with chloroform/methanol $(5: 1)$. The lipid extract was saponified (12) and aliquots were taken for determination of the cholesterol by the Lieberman-Burchard method, and for determination of radioactivity after evaporation of the solvent and addition of Instafluor (Packard Instrument International S.A., Zurich, Switzerland). The vials were counted in a liquid scintillation counter (Packard Instrument Co., Inc., Downers Grove, IL) to a standard deviation of $<1 \%$. Overlap and efficiency were controlled by reference to calibrated samples of ${ }^{3} \mathrm{H}$ and ${ }^{14} \mathrm{C}$-toluene (Amersham International).

The average free and esterified cholesterol-specific activities of total plasma and of each lipoprotein fraction during the experimental period were calculated from the area under the specific activity-time curves. Tissue samples were minced and lipids were extracted during a period of $24 \mathrm{~h}$ with $20 \mathrm{vol}$ of chloroform/methanol 2:1 (vol/vol) (13). The filtered lipid extract was washed (13).

In order to save the greater part, i.e., $95 \%$ of the lipid extract, from the tissues for radioactivity determination, the masses of free cholesterol before and after saponification of aliquots of the lipid extract were determined by a micromethod in which the fluorescences of the spots containing $0.1-0.7 \mathrm{nmol}$ free cholesterol on TLC plates were quantified in situ, using a Vitatron ILD 100 Universal densitometer (14).

One-third of the lipid extract was used for determination of total cholesterol radioactivity. The remaining extract was used for separation of free and esterified cholesterol by TLC followed by determination of the radioactivity in these fractions. Loss by TLC was $2-7 \%$. Tissue samples exposed to labeled plasma in the patients for only $0.2-0.7 \mathrm{~h}$ contained so small amounts of radioactivity that the entire lipid extract was used for determination of total cholesterol radioactivity.

The tissue samples were counted to a standard deviation of $1 \%$ or $300 \mathrm{~min}$, which for some of the low counting samples resulted in a standard deviation of up to $5 \%$ of the net counts in each channel. An exception to that was the tissue samples from the $0.2-0.7 \mathrm{~h}$ study, which in some cases contained indetectable levels of labeled cholesterol. 
In order to monitor a possible contamination of the low counting samples, the blank samples in each series contained lipid extract from human aortic tissue, which had not been exposed to labeled plasma. Such samples went through the entire analytical procedure together with the samples from patients who were injected with labeled plasma.

Influx calculations. The influx of esterified cholesterol $\left(\mathrm{K}_{\mathrm{E}}\right)$ in nanomoles $\times \mathrm{cm}^{-2} \times \mathrm{day}^{-1}$ was calculated by the so called sink or integral method, in which the amount of radioactivity in the tissue $t(\mathrm{E})$ in $\mathrm{cpm} \times \mathrm{cm}^{-2}$ was divided by the average specific activity in plasma $s(E)$ expressed in $\mathrm{cpm} \times \mathrm{nmol}^{-1}$ and by the duration of the experimental period $T$ in days. The influx of free cholesterol $\left(\mathrm{K}_{\mathrm{F}}\right)$ was calculated in a similar manner (15).

$\mathrm{K}_{\mathrm{E}}=[t(\mathrm{E})] /[s(\mathrm{E}) \times T], \quad$ and $\quad \mathrm{K}_{\mathrm{F}}=[t(\mathrm{~F})] /[s(\mathrm{~F}) \times T]$.

Labeled esterified cholesterol may be hydrolyzed in the arterial tissue subsequent to its entrance, and labeled free cholesterol may be esterified. These conversions are taken into account in a set of simultaneous influx equations which have been developed and discussed in detail elseqhere in connection with their use in hypercholesterolemic rabbits $(8,9,16)$.

$$
\begin{aligned}
& t\left({ }^{*} \mathrm{E}\right)=\mathrm{K}_{\mathrm{E}} \times T \times s\left({ }^{*} \mathrm{E}\right)-\mathrm{H} \times s\left({ }^{*} \mathrm{E}\right)+\mathrm{S} \times s\left({ }^{*} \mathrm{~F}\right), \\
& t\left({ }^{\circ} \mathrm{E}\right)=\mathrm{K}_{\mathrm{E}} \times T \times s\left({ }^{\circ} \mathrm{E}\right)-\mathrm{H} \times s\left({ }^{\circ} \mathrm{E}\right)+\mathrm{S} \times s\left({ }^{\circ} \mathrm{F}\right), \\
& t\left({ }^{*} \mathrm{~F}\right)=\mathrm{K}_{\mathrm{F}} \times T \times s\left({ }^{*} \mathrm{~F}\right)+\mathrm{H} \times s\left({ }^{*} \mathrm{E}\right)-\mathrm{S} \times s\left({ }^{*} \mathrm{~F}\right), \\
& t\left({ }^{\circ} \mathrm{F}\right)=\mathrm{K}_{\mathrm{F}} \times T \times s\left({ }^{\circ} \mathrm{F}\right)+\mathrm{H} \times s\left({ }^{\circ} \mathrm{E}\right)-\mathrm{S} \times s\left({ }^{\circ} \mathrm{F}\right),
\end{aligned}
$$

where ${ }^{*}={ }^{3} \mathrm{H},{ }^{\circ}={ }^{14} \mathrm{C}$, and the amount of newly entered esterified cholesterol in $\mathrm{nmol} \times \mathrm{cm}^{-2}$ which had been hydrolyzed in the aortic tissue, and the amount of newly entered free cholesterol in $\mathrm{nmol}$ $X \mathrm{~cm}^{-2}$ which had been esterified during the $T$ days-long experimental period are named $\mathrm{H}$ and $\mathrm{S}$, respectively.

Eqs. 2-5 can only be solved if they are independent. This is the case when: $\left[s\left({ }^{*} \mathrm{E}\right) / s\left({ }^{*} \mathrm{~F}\right)\right] \neq\left[s\left({ }^{\circ} \mathrm{E}\right) / s\left({ }^{\circ} \mathrm{F}\right)\right]$. The formulation of Eqs. $1-5$ is based on the assumption that $s(\mathrm{E})$ is the same in all lipoprotein fractions for ${ }^{3} \mathrm{H}$ and ${ }^{14} \mathrm{C}$, respectively, and that this is also true for $s(\mathrm{~F})$. Furthermore, it is assumed that the efflux of labeled cholesterol from the tissue is negligible during the experimental period compared with the influx of labeled cholesterol. Also, the amount of labeled cholesterol in contaminating plasma on the tissue should be negligible compared with the amount which has entered during the uptake period.

\section{Results}

The in vitro-labeled dose. Incorporation of labeled free cholesterol into esterified plasma cholesterol reached a maximum of $40-50 \%$ after $48 \mathrm{~h}$ in vitro incubation at $37^{\circ} \mathrm{C}$. Incubation of plasma at $4^{\circ} \mathrm{C}$ resulted in only negligible esterification of labeled free cholesterol. The amounts of ${ }^{3} \mathrm{H}$ and ${ }^{14} \mathrm{C}$ radioactivities in free and esterified cholesterol in a plasma preparation incorporated with labeled free cholesterol after $48 \mathrm{~h}$ incubation at $4^{\circ} \mathrm{C}$ and $37^{\circ} \mathrm{C}$, respectively, mixed and incubated for $1 \mathrm{~h}$ at $37^{\circ} \mathrm{C}$, are shown in Table I. About $40 \%$ of the ${ }^{14} \mathrm{C}$ cholesterol and $\sim 3 \%$ of the ${ }^{3} \mathrm{H}$-cholesterol were esterified after these incubations. ${ }^{3} \mathrm{H}$ - and ${ }^{14} \mathrm{C}$-cholesterol have a similar percentage distribution between the three plasma lipoproteins, very low density lipoprotein (VLDL), low density lipoprotein
Table I. Isotopic Composition of Human Plasma Labeled In Vitro with ${ }^{3} \mathrm{H}$ - and ${ }^{14} \mathrm{C}$-Cholesterol in Such a Way that ${ }^{3} \mathrm{H}$ Was

\begin{tabular}{|c|c|c|c|c|}
\hline & \multicolumn{2}{|c|}{$\begin{array}{l}\text { Esterified } \\
\text { cholesterol }\end{array}$} & \multicolumn{2}{|c|}{ Free cholesterol } \\
\hline & ${ }^{3} \mathrm{H}$ & ${ }^{14} \mathrm{C}$ & ${ }^{3} \mathrm{H}$ & ${ }^{14} \mathrm{C}$ \\
\hline Total plasma* & 143 & 710 & 4,968 & 1,063 \\
\hline \multicolumn{5}{|l|}{ VLDL $\ddagger$} \\
\hline$(d<1.019)$ & 6 & 19 & 23 & 24 \\
\hline \multicolumn{5}{|l|}{ LDL $\ddagger$} \\
\hline$(1.019<d<1.063)$ & 24 & 46 & 56 & 56 \\
\hline \multicolumn{5}{|l|}{ HDL $\ddagger$} \\
\hline$(d>1.063)$ & 70 & 36 & 21 & 20 \\
\hline
\end{tabular}
Nearly Exclusively in Free Cholesterol while ${ }^{14} \mathrm{C}$ Was Present in both Free and Esterified Cholesterol. A Volume of $14 \mathrm{ml}$ of this Preparation Was Intravenously Injected into Patient NK

$* \mathrm{cpm} \times \mu \mathrm{l}^{-1}$

$\ddagger \%$ of label.

(LDL), and high density lipoprotein (HDL). Labeled esterified cholesterol formed in vitro after incubation for $1 \mathrm{~h}$ is primarily present in HDL (70\%), with only a small amount in VLDL (6\%). After $48 \mathrm{~h}$ of incubation at $37^{\circ} \mathrm{C}$, the $\mathrm{HDL}$ contains relatively less $(36 \%)$ and the VLDL relatively more $(19 \%)$ of the labeled esterified cholesterol compared with the distribution after $1 \mathrm{~h}$.

We investigated the doses by column chromatography on Bio-Gel A 50 M, 30-100 mesh (Bio-rad Laboratories, Richmond, CA). The column was $1 \times 100 \mathrm{~cm}$ and the elution buffer was $5 \mathrm{mM}$ Tris- $\mathrm{HCl}$, pH 7.4, $150 \mathrm{mM} \mathrm{NaCl}, 0.5 \mathrm{mM}$ EDTA. This gel was used because human plasma lipoproteins from fasting plasma which had not been incubated or added cholesterol dissolved in ethanol was found to be within its fractionation range. The labeled cholesterol profile of the dose and of a plasma sample from a patient $1 \mathrm{~h}$ after the dose was injected were nearly superimposable. The $1-\mathrm{h}$ sample is assumed to contain only intact plasma lipoproteins.

By increasing the concentration of cholesterol in the ethanol subsequently added to plasma, an increasing percentage of the radioactivity appeared in the column's void volume. This demonstrated the formation of unphysiologically large particles, which contain some of the added cholesterol. Previously a similar observation has been reported by others $(17,18)$. After intravenous injection of such a dose, that fraction of radioactivity which appeared in the void volume was rapidly removed from the patient's plasma, since it did not occur in a sample drawn from the patient's circulation $1.0 \mathrm{~h}$ after the injection. The large particles could not be demonstrated in the in vitro labeled plasma if the concentration of cholesterol in ethanol was below $2.5 \mu \mathrm{mol} / \mathrm{ml}$ and the plasma sample was incubated at $37^{\circ} \mathrm{C}$ for $48 \mathrm{~h}$ after addition of the ethanol. When the plasma was incubated at $4^{\circ} \mathrm{C}$, the concentration of cholesterol in ethanol should be even lower. 
In an attempt to circumvent the long incubation period necessary for the formation of labeled cholesteryl ester by the lecithin/cholesterol acyltransferase activity in plasma, we dissolved labeled cholesteryl oleate (cholesteryl-1,2,6,7- ${ }^{3} \mathrm{H}(\mathrm{N})$ ) (New England Nuclear, Boston, MA) in ethanol or in acetone before addition to plasma. Even with very low cholesteryl ester concentration in the organic solvent $(<0.04 \mu \mathrm{mol} / \mathrm{ml})$, however, a significant fraction of the label $(>30 \%)$ appeared in the column's void volume. This labeling procedure was consequently abandoned.

Injection of the in vitro-labeled plasma. Fig. 1 shows the amount of radioactivity in plasma, expressed as a percentage of the injected dose in a patient who was injected with two plasma preparations which both had been incubated for $48 \mathrm{~h}$ with labeled cholesterol before the injection. The decline of labeled free cholesterol was initially much faster than that of labeled esterified cholesterol.

The volumes of distribution of the labeled free and esterified cholesterol were calculated by an extrapolation of the plasma radioactivity back to zero time. The extrapolation was based on a single exponential function of time, defined by the first two plasma samples obtained at 0.2 and $1 \mathrm{~h}$, respectively. The volumes were similar in free and in esterified cholesterol for both ${ }^{3} \mathrm{H}$ and ${ }^{14} \mathrm{C}$ in each patient. This was true both when the label was evenly distributed between free and esterified cholesterol in the dose (Fig. 1) as well as when free cholesterol in the dose was labeled preferentially (Fig. 2). The calculated volumes were between $30-45 \mathrm{ml} / \mathrm{kg}$, which is within the range of plasma volumes determined in humans by other methods (19). This indicates that the injected doses did not contain appreciable amounts of label in unphysiological particles that would have been removed during the first few minutes by the Kupffer cells of the liver (20), and thereby would have increased the calculated plasma volume.

Plasma contamination. Table II shows the data obtained from six normocholesterolemic male patients who were intravenously injected with autologous in vitro-labeled plasma $0.2-$ $0.7 \mathrm{~h}$ before the tissue was removed. In two of the patients

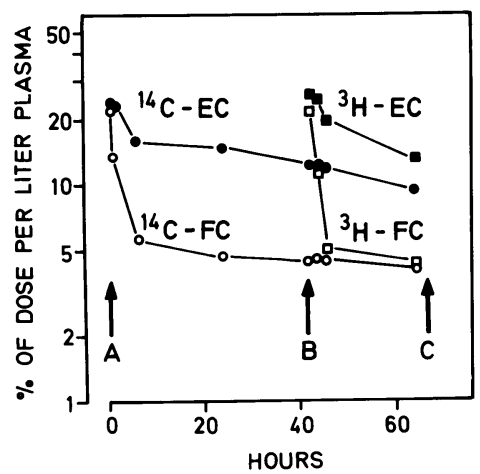

Figure 1. In this patient (MH) it was studied to what extent the amount of radioactivity found in the tissue was affected by the variation in the time from injection of the labeled lipoproteins until the aortic tissue was removed. A bolus of autologous plasma labeled with ${ }^{14} \mathrm{C}$ in free cholesterol (FC) and also in esterified cholesterol (EC) was intravenously injected

at $\mathrm{A}, 68 \mathrm{~h}$ before the operation at $\mathrm{C}$. Another bolus labeled in the same manner but with ${ }^{3} \mathrm{H}$ was injected at $\mathrm{B}$, which was $24 \mathrm{~h}$ before the operation.

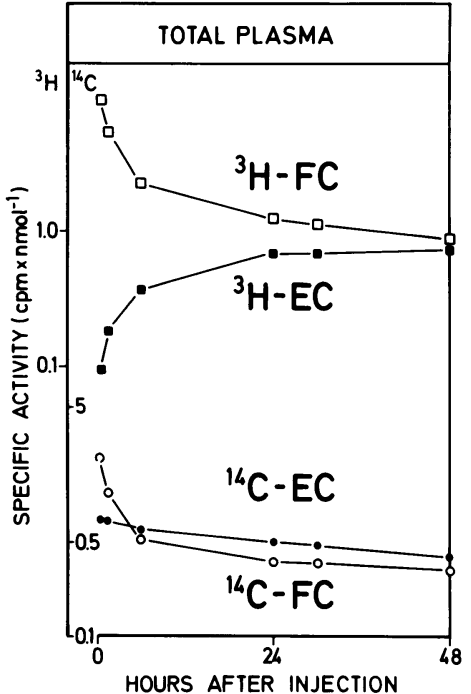

(HK and EL), $>90 \%$ of the radioactivity in plasma was present in free cholesterol with the remaining $<10 \%$ being present in esterified cholesterol. In the other patients the radioactivity was more evenly distributed between free and esterified cholesterol. For several of the patients the amounts of labeled cholesterol found in the inner and middle layers of the aortic tissue were indetectable, i.e., $<2$ net counts for ${ }^{3} \mathrm{H}$ and $<1$ net count for ${ }^{14} \mathrm{C}$. The adventitial layer contained much more radioactivity than the other layers. If it is assumed that all the radioactivity in the tissue is due to plasma contamination, this contamination can be expressed in nanoliter plasma per $\mathrm{cm}^{2}$ intimal surface (Table II). These values represent a maximum estimate of the contamination, since some of the labeled cholesterol from plasma probably had entered the tissue even during the $0.2-0.7-\mathrm{h}$ period. The values found for the inner and for the middle layer of the aortic tissue from patient LM were much higher than the corresponding values in the other five patients. Just before removal of the aortic tissue this patient had several attacks of ventricular fibrillation which were treated with electric defibrillation. The values from the patient were therefore not considered typical and they are not included in the mean values for the plasma contamination.

Labeled cholesterol in plasma. Fig. 2 shows the specific activities in total plasma from the time of injection of a dose containing ${ }^{3} \mathrm{H}$ and ${ }^{14} \mathrm{C}$ differently distributed between free and esterified cholesterol until the aortic tissue was removed. The specific activities of ${ }^{3} \mathrm{H}$ and ${ }^{14} \mathrm{C}$ free cholesterol decreased in parallel on this semilogarithmic plot. In contrast, the specific activity of ${ }^{3} \mathrm{H}$ esterified cholesterol increased, while at the same time the specific activity of ${ }^{14} \mathrm{C}$ esterified cholesterol decreased. This difference can be ascribed to esterification, which is more visible in ${ }^{3} \mathrm{H}$ esterified than in ${ }^{14} \mathrm{C}$ esterified cholesterol, because of the initial lack of ${ }^{3} \mathrm{H}$ esterified cholesterol in the dose (Table I). Hydrolysis and esterification tended to equalize the specific activities of free and esterified cholesterol in plasma for each of the two isotopes during $48 \mathrm{~h}$. 


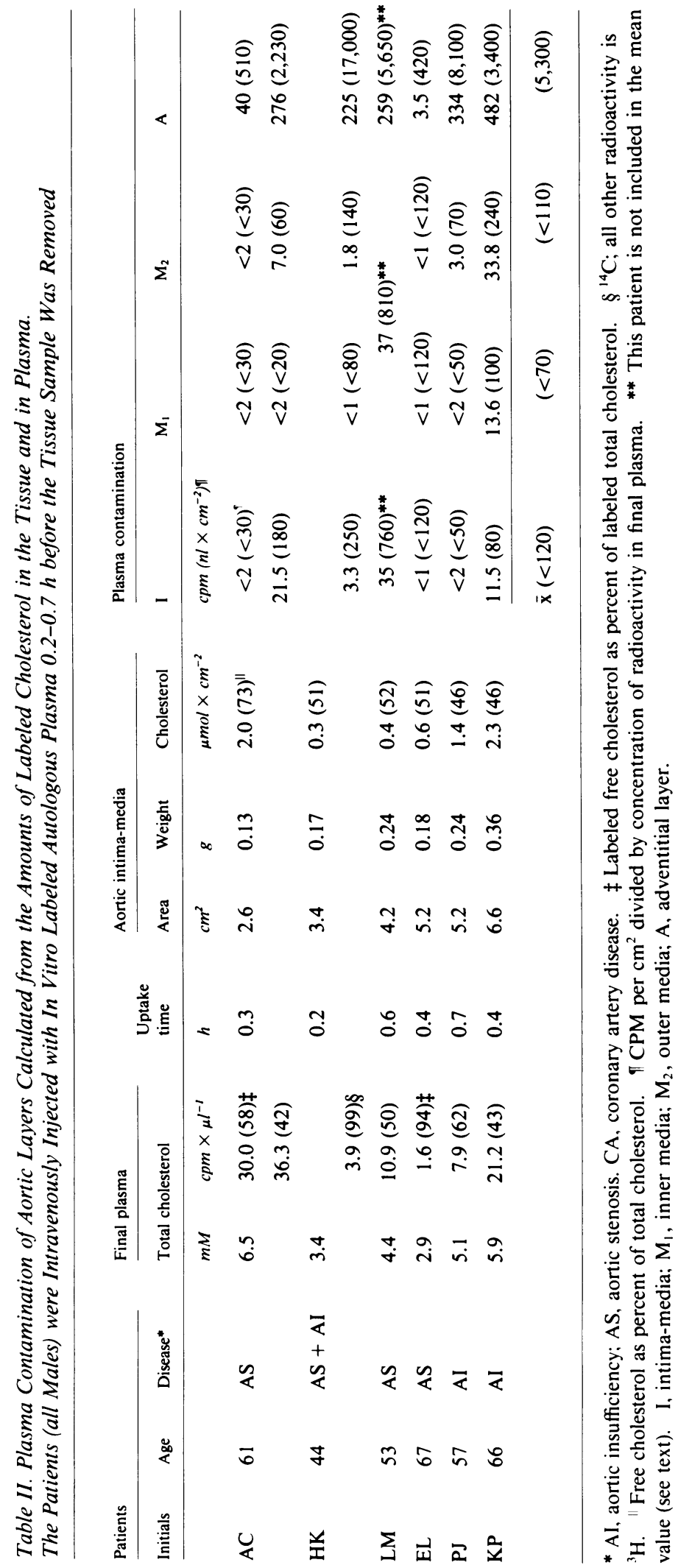

1875 Arterial Cholesterol Influx in Man 


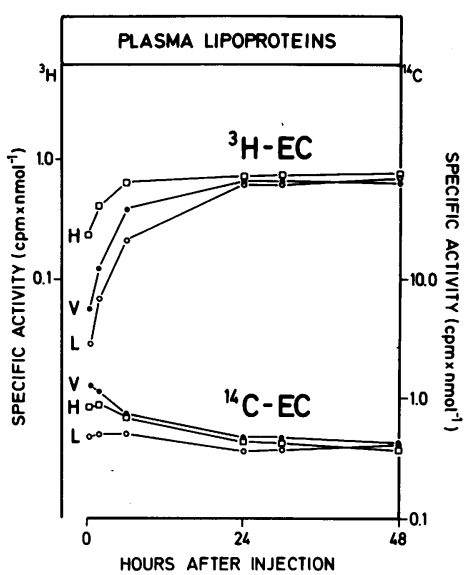
for the specific activity of ${ }^{14} \mathrm{C}$ in free cholesterol. The contents of ${ }^{3} \mathrm{H}$ and ${ }^{14} \mathrm{C}$ in free and esterified cholesterol in the three lipoprotein fractions of the injected plasma dose are shown in Table $\mathrm{I}$.

The specific activities of free cholesterol were nearly the same in all the lipoprotein fractions during the entire time period. The relatively high specific activity of ${ }^{3} \mathrm{H}$ in $\mathrm{HDL}$ esterified cholesterol immediately after injection disappeared $24 \mathrm{~h}$ later (Fig. 3). The specific activity of ${ }^{3} \mathrm{H}$ in esterified cholesterol in LDL was somewhat lower during that period, with esterified cholesterol in VLDL having intermediate values. For the ${ }^{14} \mathrm{C}$ which was nearly evenly distributed between free and esterified cholesterol in the dose, the specific activity in VLDL cholesteryl ester was always initially much higher than in the other fractions. After a few hours that difference disappeared (Fig. 3). The average specific activities calculated over a period exceeding $48 \mathrm{~h}$ were rather similar for each of the isotopes in the free and in the esterified cholesterol of the various lipoproteins (Table III).

The mean values of the specific activities for free and esterified plasma cholesterol are given for all the patients who were intravenously injected with cholesterol labeled plasma 24-114 $\mathrm{h}$ before the operation (Table IV). The first three patients in the table were injected first with one preparation and then later with another. One patient (ES) was used to control for isotope equivalency. The last five patients in the table were intravenously injected with plasma in which ${ }^{3} \mathrm{H}$ and ${ }^{14} \mathrm{C}$ were differently distributed between free and esterified cholesterol.

Cholesterol in the aortic tissue. The surface of the intimamedia layer of the tissues used in the present investigation were all without macroscopically visible lesions. The ${ }_{s}$ concentrations of free and esterified cholesterol in each of the aortic layers from three of the patients are shown on the left panel of Fig. 4. In these three and in all the other patients the highest cholesterol concentrations were found in the intima-media layer and the lowest in the adventitial layer. Esterified cholesterol expressed as a percentage of total cholesterol was highest in the intima-media layer and lowest in the adventitial layer. The wet weight of each layer divided by the area of the corresponding intimal surface is given in the legend to Fig. 4 . If the density of the tissue is assumed to be 1.0 , the values times 10 is the thickness of the layer in $\mu \mathrm{m}$.

Labeled cholesterol in the aortic tissue. The right panel of Fig. 4 shows the amount of ${ }^{3} \mathrm{H}$ and ${ }^{14} \mathrm{C}$ radioactivity in the total cholesterol of each layer of the aortic tissue that was obtained from the first three patients in Table IV. The values are expressed as a percentage of the amounts of ${ }^{3} \mathrm{H}$ - and ${ }^{14} \mathrm{C}$-cholesterol which were intravenously injected in the patients. The number of hours between injection of the first dose and the operation and between injection of the second dose and the operation are indicated for each patient.

In these three patients and in the other six patients from Table IV, the radioactive cholesterol found in the aortic tissue after $24-114 \mathrm{~h}$ in vivo exposure to labeled cholesterol in plasma showed the same pattern, a low sometimes indetectable level of radioactivity in one or two of the middle layers compared with the radioactivity in the adjacent more luminal and abluminal layers. When the tissue was removed $0.3-0.7 \mathrm{~h}$ after injection of the labeled plasma the pattern was different (Table II), with much more radioactive cholesterol in the adventitial layers than in the more luminal layers.

Table III. Mean Values of Specific Activities and Cholesterol Concentrations in Plasma Lipoprotein Fractions from Patient NK from Injection of the Dose (Table I) until the Tissue Was Removed 48 h Later

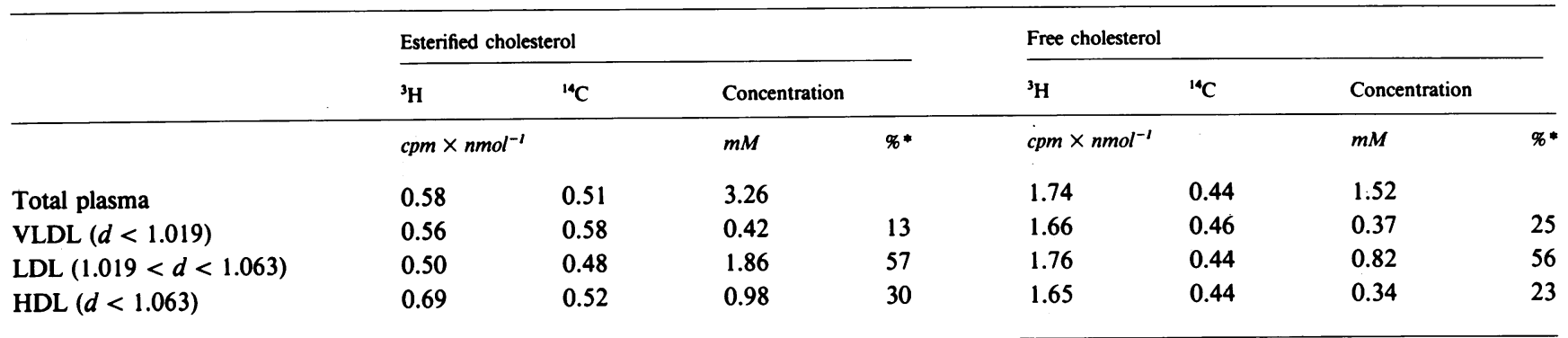

* Percent of total plasma esterified and free cholesterol, respectively. 
Table IV. Labeled Cholesterol in Plasma and in Aortic Intima-media in Patients Intravenously Injected with Autologous In Vitro Labeled Plasma before the Tissue Specimen Was Obtained

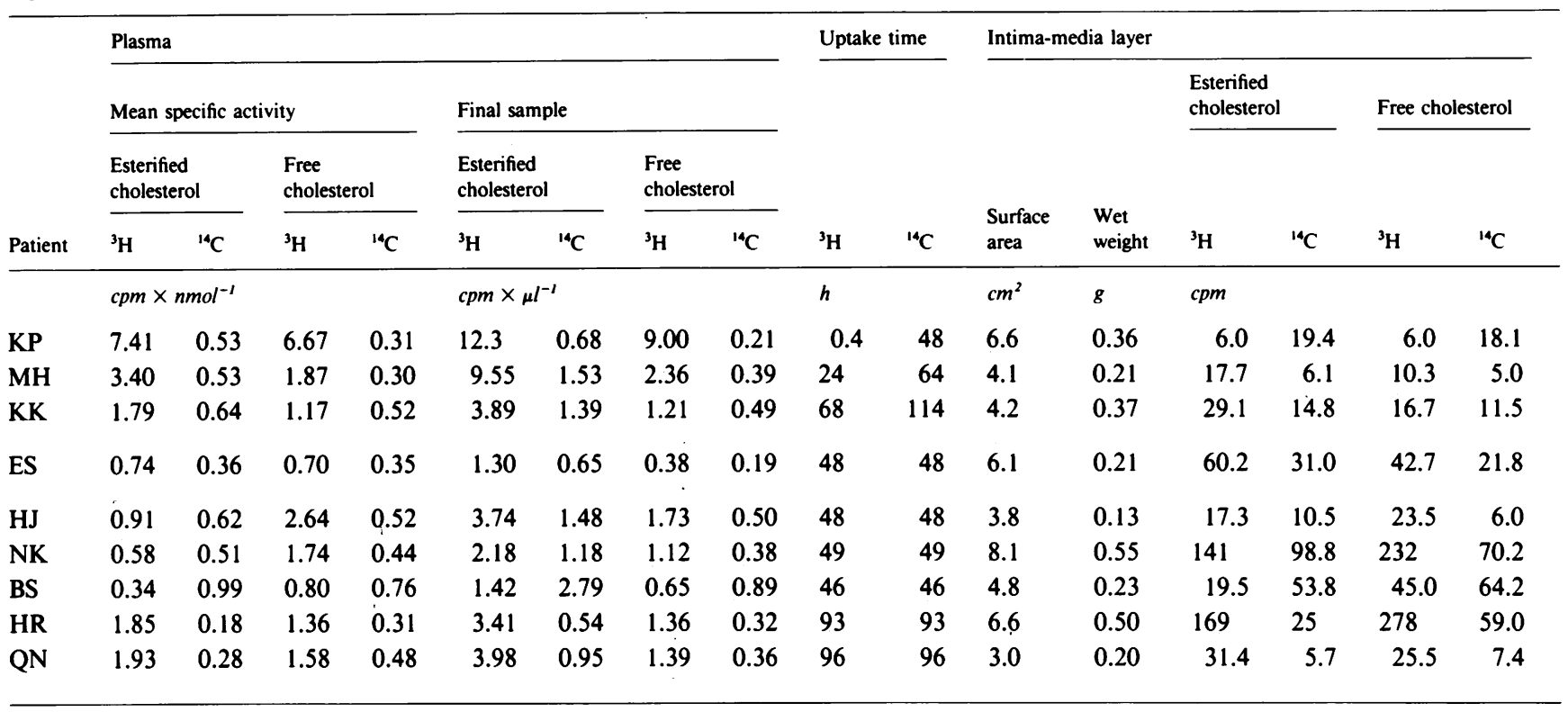

For the first patient (KP), radioactive cholesterol in the two inner layers, corresponding to an approximate thickness of $1 \mathrm{~mm}$, after $48 \mathrm{~h}$ far exceeded the radioactive cholesterol present after $0.5 \mathrm{~h}$, whereas there was a net loss of radioactive cholesterol from the two outer layers during $48 \mathrm{~h}$. In patient $\mathrm{MH}$ the fraction of the injected labeled cholesterol found in the inner layer was higher after $64 \mathrm{~h}$ than after $24 \mathrm{~h}$. This meant that a continued accumulation of labeled cholesterol occurred during the period between 24 and $64 \mathrm{~h}$ after injection of the dose. In contrast, the fraction of the injected dose of labeled cholesterol found in the outer layers was lower after $64 \mathrm{~h}$ than after $24 \mathrm{~h}$. This meant that a net loss of labeled cholesterol from these layers took place during the same period. The same pattern was seen in patient KK (Fig. 4) during the period between 68 and $114 \mathrm{~h}$ after the injection.

These data taken together with the values for plasma contamination in the outer aortic layers (Table II), show that a considerable fraction of labeled cholesterol in this part of the tissue even after a 24-114 $\mathrm{h}$ uptake period can be ascribed to contaminating plasma. The net loss of labeled cholesterol from the outer layers (Fig. 4) probably reflect the rapid decline in the concentration of radioactive cholesterol in contaminating plasma, which can not be removed from vasa vasorum during the washing procedure.

The inner layer, on the other hand, showed a continued accumulation of radioactive cholesterol at least up to $114 \mathrm{~h}$ (Fig. 4). The concentration of labeled cholesterol in the plasma immediately before the tissue was removed from the circulation are shown for each patient in Table IV, together with the amounts of labeled cholesterol in the inner layer of the aortic tissue. A plasma contamination of $\sim 0.1 \mu \mathrm{l} / \mathrm{cm}^{2}$, as calculated in Table II, thus contributes negligible amounts of radioactive cholesterol to the amounts found in the inner layer after an uptake period of $24-96 \mathrm{~h}$. This is also shown by the data obtained in patient NK (Fig. 4, upper frames). Therefore, only the inner layers of the aortic tissue were used for the following influx calculations.

Calculation of influx. A crude influx of esterified and of free cholesterol from plasma into the inner aortic layer were calculated from Eq. 1 and the ${ }^{3} \mathrm{H}$ and ${ }^{14} \mathrm{C}$ data in Table IV. These influx values (Table $\mathrm{V}$ ) show a large interindividual variation with no clear relation to the duration of the experimental period. Low values were found in a patient (QN) with an uptake period of $96 \mathrm{~h}$ but also in a patient with an uptake period of $24 \mathrm{~h}\left(\mathrm{MH},{ }^{3} \mathrm{H}\right)$. When a crude influx was calculated for the same patient based on a short and a longer uptake period (patients $\mathrm{MH}$ and $\mathrm{KK}$ ), the two values differed with only $10-20 \%$.

The last five patients in Table $\mathrm{V}$ were injected with labeled plasma in which the ratio between the specific activities in free and esterified cholesterol was different for ${ }^{3} \mathrm{H}$ and ${ }^{14} \mathrm{C}$ (see Table I). This difference was gradually diminished in the patients' plasma during the days after the injection due to in vivo esterification and hydrolysis of the labeled sterols. The mean values in plasma during the uptake period still showed a considerable difference with a higher fraction of one of the isotopes in free cholesterol when compared with the fraction of the other isotope in free cholesterol (Table V). This is a condition for the use of Eqs. 2-5. These equations take into account that labeled sterols in the aortic tissue may be hydro- 


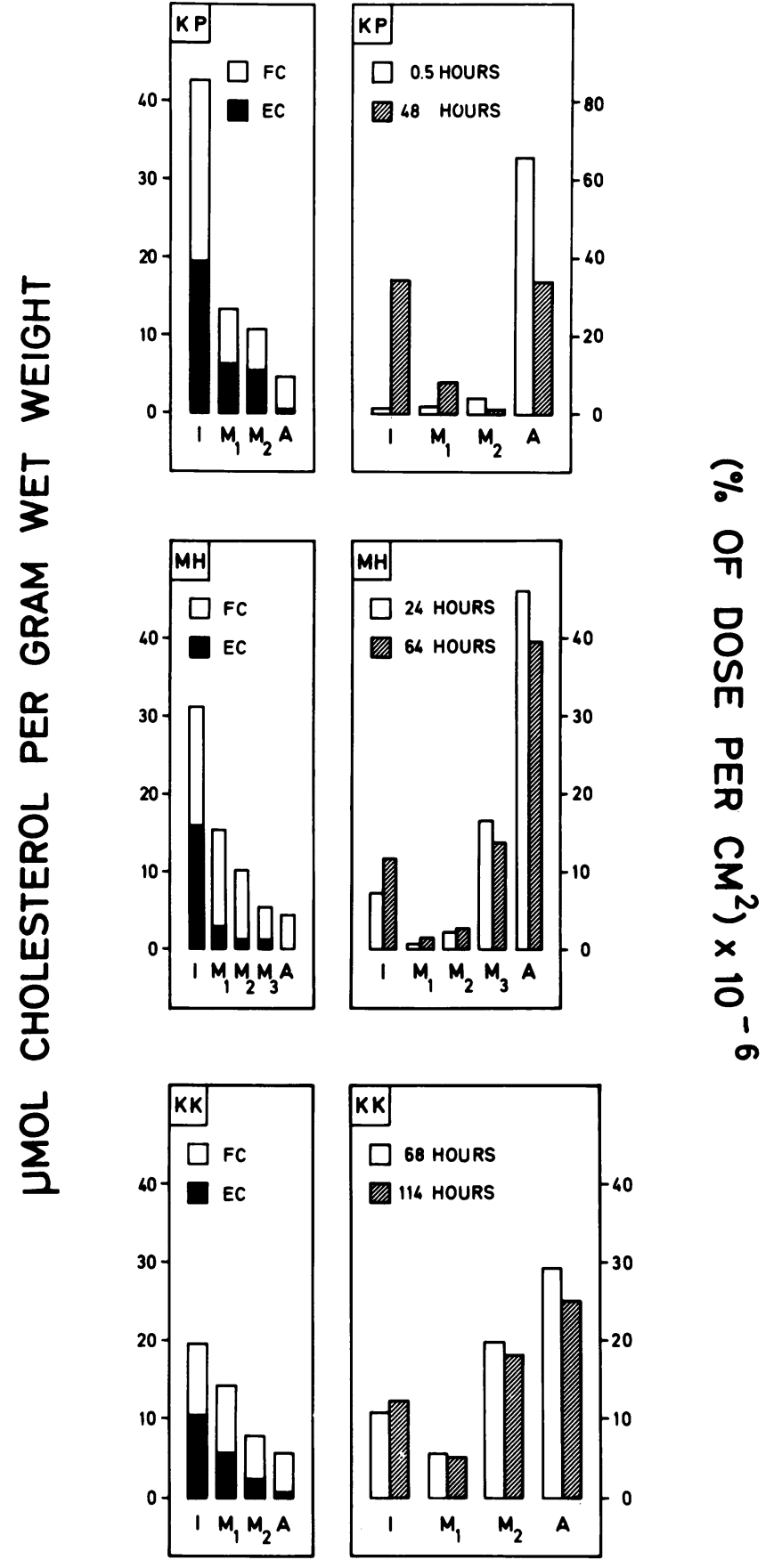

Figure 4. The left panel shows the concentrations of free and esterified cholesterol in each of the four or five layers of the ascending thoracic aorta of three patients. The wet weights per $\mathrm{cm}^{2}$ surface area of $I, M_{1}, M_{2}$, and A for $K P$ were: $55,46,33$, and 30 , respectively. For MH the values were: $51,29,34,24$, and 42 ; and for KK the values were: $31,57,45$, and 19 . The right panel shows the amount of radioactivity present in total cholesterol in the various layers of the ascending thoracic aorta, expressed as percent of the amount of labeled cholesterol injected into the patient. The hatched bars refer to the first dose which was injected into the patients. The unhatched bars refer to the dose which was injected several hours later.
Table V. Crude Influx Values for the In Vivo Transfer of Free and of Esterified Cholesterol from Plasma into the Intima-media Layer of the Ascending Aorta from Humans

\begin{tabular}{|c|c|c|c|c|c|c|}
\hline \multirow[b]{3}{*}{ Patient } & \multicolumn{4}{|c|}{ Crude influx* } & \multirow{2}{*}{\multicolumn{2}{|c|}{$\begin{array}{l}\text { Plasma } \\
\frac{\text { Free } \times 100 \ddagger}{\text { Total }}\end{array}$}} \\
\hline & \multicolumn{2}{|c|}{$\begin{array}{l}\text { Esterified } \\
\text { cholesterol }\end{array}$} & \multicolumn{2}{|c|}{ Free cholesterol } & & \\
\hline & ${ }^{3} \mathrm{H}$ & ${ }^{14} \mathrm{C}$ & ${ }^{3} \mathrm{H}$ & ${ }^{14} \mathrm{C}$ & ${ }^{3} \mathrm{H}$ & ${ }^{14} \mathrm{C}$ \\
\hline & \multicolumn{4}{|c|}{$\mathrm{nmol} \times \mathrm{cm}^{-2} \times d a y^{-1}$} & \multicolumn{2}{|l|}{$\%$} \\
\hline $\mathrm{MH}$ & 1.3 & 1.1 & 1.3 & 1.5 & 20 & 20 \\
\hline KK & 1.4 & 1.2 & 1.2 & 1.1 & 22 & 27 \\
\hline ES & 6.7 & 7.1 & 5.0 & 5.1 & 29 & 29 \\
\hline HJ & 2.5 & 2.2 & 1.2 & 1.5 & 56 & 27 \\
\hline NK & 14.7 & 11.7 & 8.1 & 9.7 & 58 & 28 \\
\hline BS & 6.2 & 5.9 & 6.1 & 9.2 & 49 & 24 \\
\hline HR & 3.6 & 5.4 & 8.0 & 7.4 & 26 & 45 \\
\hline QN & 1.4 & 1.7 & 1.3 & 1.3 & 25 & 42 \\
\hline
\end{tabular}

* Labeled free and esterified cholesterol in the tissue divided by the area below the corresponding specific activity versus time curve. $¥$ The mean value of the concentration of labeled free cholesterol in plasma divided by the mean value of the concentration of labeled free plus esterified cholesterol in plasma.

lyzed and esterified. The corrected values are shown in Table VI together with other data about the patients.

Isotope equivalency. In interpretation of the ${ }^{3} \mathrm{H}$ and ${ }^{14} \mathrm{C}$ data it is assumed that ${ }^{3} \mathrm{H}$ - and ${ }^{14} \mathrm{C}$-labeled cholesterol behave identically with respect to uptake by the human arterial wall. It has been reported in studies with labeled cholesterol in humans that the ${ }^{3} \mathrm{H}$ - and ${ }^{14} \mathrm{C}$-labeled species of cholesterol behave differently (21). We therefore added a mixture of ${ }^{3} \mathrm{H}$ and ${ }^{14} \mathrm{C}$-cholesterol dissolved in ethanol to a plasma sample, incubated the sample for $48 \mathrm{~h}$, and injected it intravenously into a patient (ES). The crude influx values for free and esterified cholesterol based on ${ }^{3} \mathrm{H}$ and ${ }^{14} \mathrm{C}$, respectively, are similar (patient ES, Table V). We therefore consider the batches of ${ }^{3} \mathrm{H}$ - and ${ }^{14} \mathrm{C}$-cholesterol, which have been used in the present study, to behave identically in their interaction with the arterial wall.

\section{Discussion}

Labeled cholesterol in the patients' plasma. When the lipoproteins labeled in free and esterified cholesterol were injected into the patients, neither of these labeled compounds remained in the injected lipoprotein particles, but underwent exchange with the unlabeled free and esterified cholesterol in the endogenous lipoproteins in the blood of the patient. Since exchange is a rapid process and since the amount of injected lipoproteins was very small compared with the amount of circulating lipoproteins, the arterial tissue was exposed to in vivo-labeled 
endogenous lipoproteins for the major part of the experimental period. The amount of radioactivity found in the arterial tissue 0.3-0.7 $\mathrm{h}$ after injection of the dose was only a minor fraction of the radioactivity found in the tissue after 24-114 $\mathrm{h}$ exposure to plasma labeled with cholesterol. Labeled cholesterol in the intima-media tissue can therefore not be ascribed to a preferential uptake of labeled lipoproteins which have been partly denatured during the labeling procedure, but rather results from an interaction between intact lipoproteins and the tissue.

The exchange of free cholesterol between lipoproteins in plasma keeps the ${ }^{3} \mathrm{H}$ - and ${ }^{14} \mathrm{C}$-free cholesterol evenly distributed between the lipoproteins in the dose (Table I) as well as in the patient (Table III). For calculation of the cholesteryl ester influx it is assumed that each fraction of cholesteryl ester which enters the tissue has the same mean specific activity as that found in the total plasma cholesteryl ester pool. This is not quiet true, even for uptake periods as long as $48 \mathrm{~h}$ (Table III), as VLDL provides too much labeled cholesteryl ester to the tissue compared with its influx, when a large fraction of the label in the dose is esterified cholesterol $\left({ }^{14} \mathrm{C}\right.$-values in Fig. 3). This also applies to HDL when the dose contains a large fraction of its label in free cholesterol $\left({ }^{3} \mathrm{H}\right.$-values in Fig. 3). This is more pronounced after periods of only $24 \mathrm{~h}$.

Influx of free and esterified cholesterol and duration of uptake period. The shorter the time from injection of the dose until the tissue is removed, the lesser does efflux of labeled sterols from the intima-media tissue reduce the crude influx, as calculated with Eq. 1. The rather similar values which were obtained when the influx was calculated in the same patient $(\mathrm{MH})$ for 24 and $64 \mathrm{~h}$, respectively, and in another patient (KK) (Table V) for 68 and $114 \mathrm{~h}$, respectively, is an accordance with an uptake of labeled free and esterified plasma cholesterol without major changes of the labeled sterols in the tissue during the first 2-4 d. The changes could result from esterification of labeled free cholesterol, hydrolysis of labeled esterified cholesterol, and efflux of one or both types of the labeled sterols. Such an efflux may be quantitatively important between 68 and $114 \mathrm{~h}$ after the injection of the dose, since the values for both free and esterified cholesterol at the latter time were 10-20\% lower than those obtained after $68 \mathrm{~h}$ exposure (patient KK, Table V).

The same type of comparison was made in a recent study of the in vivo uptake of iodionated plasma lipoproteins by human arterial tissue (22). Influx values calculated with Eq. 1 on two patients in that study were two and eight times higher at the 4-5-h uptake period than at the 24-h uptake period. This suggests a disappearance of (iodinated) apoproteins from the arterial tissue within hours, after exposure, whereas the major part of the newly entered lipoprotein cholesterol apparently remains for days. The 10-100 times lower specific activities of cholesterol in the intima-media tissue compared with cholesterol in the final plasma sample also shows that the two cholesterol pools are far from equilibrium.

The plasma contamination on the inner aortic layer was about $0.1 \mu \mathrm{l} / \mathrm{cm}^{2}$ (Table II). This value is $>10$ times higher than the corresponding value found in the thoracic aorta of rabbits (9). The relatively high value in humans may become quantitatively important when the uptake period is shortened to below 10-16 $\mathrm{h}$.

Hydrolysis and esterification in the intima-media tissue. The crude influx of free cholesterol is 0.6-1.5 times the crude influx of esterified cholesterol measured in the same patient (Table V). Free cholesterol in plasma constitutes $\sim 0.5$ times the content of esterified cholesterol in plasma (Table VI). Therefore, the crude influx of free and esterified plasma cholesterol cannot be explained exclusively by an influx of plasma lipoproteins. The crude influx of free cholesterol is relatively too large. This relation has been described also for several experimental animals $(23,24)$. The excess of labeled free cholesterol in the tissue could be attributed to hydrolysis of labeled esterified cholesterol in the intima-media subsequent to its entrance from plasma. Actually, all labeled free cholesterol in the tissue could be derived from labeled esterified cholesterol, or all labeled esterified cholesterol could be derived from labeled free cholesterol, which may have entered the tissue by an exchange process. The latter possibility was emphasized in an earlier study of cholesterol metabolism in human arterial tissue (4). The relative importance of free cholesterol exchange, hydrolysis, and esterification have previously not been determined for human arterial tissue and have been an important obstacle for the interpretation of data obtained by use of labeled cholesterol in such studies (1-4).

These processes are taken into account when influx of free and esterified cholesterol are calculated by use of Eqs. 2-5. The hydrolysis and esterification in the intima-media tissue of the labeled sterols from plasma are shown in brackets in Table VI. These values are underestimates of the total hydrolysis and esterification in the tissue, expressed in nanomoles converted cholesterol per hour, because hydrolysis of esterified cholesterol and esterification of the free cholesterol already present in the tissue before the start of the experiment are not measured by the present method. The values correct, however, the discrepancies between the crude influx values for free cholesterol and for esterified cholesterol, respectively, when these values are calculated from two isotopes which differ only in their distribution between free and esterified plasma cholesterol (Table V).

The corrected influx values in Table VI are similar to the crude influx values for the same patient in Table $V$. This shows that the crude influx calculation is rather insensitive to arterial hydrolysis and esterification, when this calculation is based on distribution of radioactivity between free and esterified plasma cholesterol, as it was encountered under the present experimental conditions. The crude influx values for the first four patients in Table $\mathrm{V}$ are therefore good estimates of the corrected influx values and are included in Table VI.

The present investigation thus shows that cholesteryl ester enters the tissue at a rate of the same magnitude as that at which free cholesterol enters. The relative excess of labeled free cholesterol in the tissue cannot be ascribed to hydrolysis of labeled esterified cholesterol, but reflects a relatively excessive influx of free cholesterol. In the last five patients in Table VI, 
Table VI. Concentrations and Influx Values Describing the In Vivo Transfer of Free and Esterified Cholesterol into Ascending Aorta of Humans

\begin{tabular}{|c|c|c|c|c|c|c|c|c|c|c|c|c|c|}
\hline \multirow{2}{*}{\multicolumn{4}{|c|}{ Patient }} & \multicolumn{4}{|l|}{ Plasma } & & & & & & \\
\hline & & & & \multicolumn{4}{|c|}{ Total cholesterol } & \multicolumn{6}{|c|}{ Intima-media layer } \\
\hline \multirow{3}{*}{ Initials } & \multirow{3}{*}{ Age } & \multirow{3}{*}{ Sex } & \multirow{3}{*}{ Disease* } & \multirow[b]{2}{*}{ Total } & \multirow[b]{2}{*}{ VLDL } & \multirow[b]{2}{*}{ LDL } & \multirow[b]{2}{*}{ HDL‡ } & \multirow[b]{2}{*}{$\begin{array}{l}\text { Wet } \\
\text { weight }\end{array}$} & \multirow[b]{2}{*}{$\begin{array}{l}\text { Total } \\
\text { cholesterol }\end{array}$} & \multicolumn{4}{|l|}{ Influx } \\
\hline & & & & & & & & & & $\begin{array}{l}\text { Esterified } \\
\text { cholesterol }\end{array}$ & $\begin{array}{l}\text { Free } \\
\text { cholesterol }\end{array}$ & Exchange ${ }^{* *}$ & $\begin{array}{l}\text { Turnoverłł } \\
\text { time }\end{array}$ \\
\hline & & & & $m M$ & & & & $\begin{array}{l}m g \\
\times \mathrm{cm}^{-2}\end{array}$ & $\begin{array}{l}\mu m o l \\
\times \mathrm{cm}^{-2}\end{array}$ & $\mathrm{nmol} \times \mathrm{cm}^{-2}$ & $<d a y^{-1}$ & $\%$ & $y r$ \\
\hline KP & 66 & $\delta$ & AI & $5.9(34) \S$ & - & - & - & 55 & $2.3(55) \S$ & 2.8 & 4.4 & & 2.3 \\
\hline MH & 58 & $\delta$ & $A I+C A$ & $4.2(31)$ & 0.5 & 2.5 & 1.2 & 51 & $1.6(49)$ & 1.3 & 1.3 & & 3.5 \\
\hline KK & 61 & $q$ & AS & $5.2(31)$ & 0.8 & 3.2 & 1.2 & 88 & $1.4(54)$ & 1.4 & 1.2 & & 2.8 \\
\hline ES & 61 & $\delta$ & AS & $4.7(29)$ & 0.5 & 3.1 & 1.1 & 34 & $2.3(81)$ & 6.7 & 5.0 & & 0.9 \\
\hline HJ & 69 & $\delta$ & $\mathrm{AS}+\mathrm{AI}+\mathrm{CA}$ & $5.6(30)$ & 0.8 & 3.5 & 1.3 & 34 & $1.0(37)$ & $2.5(16)^{11}$ & $1.1(12) \pi$ & 7 & 1.1 \\
\hline NK & 57 & $\delta$ & AS & $4.8(31)$ & 0.8 & 2.7 & 1.3 & 68 & $0.6(56)$ & $12.5(15)$ & $8.8(16)$ & 35 & 0.14 \\
\hline BS & 52 & $q$ & AS & $5.8(29)$ & 1.4 & 3.5 & 0.9 & 48 & $0.7(49)$ & $9.4(38)$ & $4.8(4)$ & 17 & 0.3 \\
\hline HR & 60 & $\delta$ & $\mathrm{AS}+\mathrm{AI}$ & $5.6(32)$ & 1.9 & 2.7 & 1.0 & 76 & $1.1(52)$ & $2.9(25)$ & $8.9(21)$ & 84 & 0.9 \\
\hline QN & 64 & $\delta$ & AS & $5.1(29)$ & 1.2 & 2.6 & 1.3 & 67 & $1.4(63)$ & $1.0(8)$ & $1.7(24)$ & 75 & 3.8 \\
\hline$\overline{\mathbf{x}}$ & 61 & & & 5.2 & 1.0 & 3.0 & 1.2 & 58 & 1.4 & 4.5 & 4.1 & & 1.7 \\
\hline SE & 2 & & & 0.2 & 0.2 & 0.1 & 0.1 & 6 & 0.2 & 1.4 & 1.0 & & 0.4 \\
\hline
\end{tabular}

* AI, aortic insufficiency; AS, aortic stenosis; CA, coronary artery disease. $\ddagger$ VLDL: $d<1.019$; LDL: $1.019<d<1.063$; HDL: $d>1.063$. $\S$ The values in brackets indicate free cholesterol as percent of total cholesterol. "Hydrolysis of esterified cholesterol in the arterial tissue as percent of the esterified cholesterol which have entered the tissue during the uptake time. T Esterification of free cholesterol in the arterial tissue as percent of the free cholesterol that have entered the tissue during the uptake time. ** Exchange is the free cholesterol influx that does not accompany the influx of esterified cholesterol: $K_{F}-\left(K_{E} \times[F] \times[E]^{-1}\right)$ where $[E]$ and $[F]$ are the concentrations in plasma of free and esterified cholesterol. Exchange is expressed as a percent of the influx of free cholesterol. vided by the influx of esterified cholesterol.

the influx of free cholesterol is partitioned between that fraction which entered the tissue in proportion to cholesteryl ester influx and to the excess of free cholesterol influx. The latter probably reflects an exchange of free cholesterol between plasma lipoproteins and the intima-media surface. This exchange influx is substantial compared to the total influx of free cholesterol (17-80\%).

The more equilibrated labeled free and esterified cholesterol are in plasma, the greater will be the possible error in the calculated values $K_{E}$ and $K_{F}$. Complete equilibrium of the mean values in plasma would correspond to the use of only one isotope. This would make the determinations of $K_{F}$ and $\mathrm{K}_{\mathrm{E}}$ impossible without further assumptions about hydrolysis and esterification in the tissues. Under the conditions of our experiments, an error analysis (11) revealed that the error in $\mathrm{K}_{\mathrm{F}}$ and $\mathrm{K}_{\mathrm{E}}$ was $5-20 \%$.

Arterial influx of cholesteryl ester. Among the nine patients there was a tenfold variation in the cholesteryl ester influx into macroscopically normal intima-media tissue. The variation was not related to a variation in cholesterol concentration in plasma or to a variation in the concentration of plasma lipoproteins (Table VI).
It is not yet known if a high cholesteryl ester influx into a luminal surface area of $4-8 \mathrm{~cm}^{2}$ is representative also for adjacent areas in the ascending aorta. Nonuniform endothelial permeability to plasma macromolecules within the same aorta has been described in experimental animals $(25,26)$. The large variation we observe in these macroscopically similar surfaces may reflect a high degree of functional heterogeneity within the same aorta and maybe also between the same location in different individuals. Heterogeneity of the aortic wall with respect to plasmalipoprotein metabolism is not surprising. The appearance of atherosclerotic lesions in the human aorta shows a large inter- and intraindividual variation, which indicates a variation in some properties of the arterial wall even before the development of macroscopically visible lesions.

The cholesteryl ester influx into the thoracic aorta of cholesterol-fed rabbits has been shown to occur as a lipoprotein flux, which is directly proportional to the concentration of the lipoproteins in the plasma and inversely proportional to the logarithm of the molecular diameter of the lipoproteins (11). In humans it is not yet known to what extent HDL, LDL, and VLDL contribute to the cholesteryl ester influx into the arterial wall. 
Removal of cholesteryl ester from intima-media tissue. A strong positive correlation has been observed in cholesterolfed rabbits between the cholesteryl ester influx into the intimamedia layer and the amount of cholesterol in that layer (11, 27). Such a correlation was not found in the ascending aorta of the patients in this study. This suggests that the cholesterol content of that tissue is also determined by something else than influx of plasma cholesterol.

The influx of cholesteryl ester from plasma into the ascending aorta is so high that it, during a 0.1-3.5-yr-period, corresponds to the cholesterol content of the tissues (Table VI, last column). Unless some of the esterified cholesterol leaves the tissue, such an influx would lead to the accumulation of huge amounts of cholesterol during a normal lifespan. Our data suggest, therefore, that removal of esterified cholesterol from aortic tissue without visible atherosclerosis represents a major importance for the cholesterol concentration in the tissue. Whether this removal takes place by an exchange-like net transfer of free cholesterol from the endothelial surface of the tissue to the plasma lipoproteins, subsequent to a hydrolysis of cholesteryl ester in the tissue, or whether it occurs as an efflux of free and esterified cholesterol with lipoproteins that have previously entered the wall remains to be determined.

\section{Acknowledgments}

This study was supported by a grant from W. M. Vett's Foundation, Copenhagen, Denmark.

\section{References}

1. Biggs, M. W., D. Kritchevsky, D. Colman, J. W. Gofman, H. B. Jones, F. T. Lindgren, G. Hyde, and T. P. Lyon. 1952. Observations on the fate of ingested cholesterol in man. Circulation. 6:359-366.

2. Field, H., L. Swell, R. E. Schools, and C. R. Treadwell. 1960. Dynamic aspects of cholesterol metabolism in different areas of the aorta and other tissues in man and their relationship to atherosclerosis. Circulation. 22:547-558.

3. Gould, R. G., R. W. Wissler, and R. J. Jones. 1963. The dynamics of lipid deposition in arteries. In Evolution of the Atherosclerotic Plaque. R. J. Jones, editor. University of Chicago Press, Chicago. 205-214.

4. Jagannathan, S. N., W. E. Connor, W. H. Baker, and A. K. Bhattacharyya. 1974. The turnover of cholesterol in human atherosclerotic arteries. J. Clin. Invest. 54:366-377.

5. Bell, F. P. 1978. Lipid exchange and transfer between biological lipid-protein structures. Prog. Lipid Res. 17:207-243.

6. Dayton, S., and S. Hashimoto. 1970. Recent advances in molecular pathology-a review. Cholesterol flux and metabolism in arterial tissue in atheromata. Exp. Mol. Pathol. 13:253-268.

7. Brockman, H. L. 1979. Enzymes of cholesteryl ester synthesis and hydrolysis in the arterial wall. In The Biochemistry of Atherosclerosis. A. M. Scanu, editor. Marcel Dekker, Inc., New York. 293-321.

8. Stender, S., and D. B. Zilversmit. 1980. Mathematical methods for the simultaneous measurement of arterial influx of esterified and free cholesterol from two lipoprotein fractions and in vivo hydrolysis of arterial cholesteryl ester. Atherosclerosis. 36:331-340.

9. Stender, S., and D. B. Zilversmit. 1981. In vivo influx, tissue esterification and hydrolysis of free and esterified plasma cholesterol in the cholesterol-fed rabbit. Biochim. Biophys. Acta. 663:674-686.

10. Thompson, J. N., P. Erdody, R. Brien, and T. K. Murray. 1971. Fluorometric determination of vitamin $A$ in human blood and liver. Biochem. Med. 5:67-89.

11. Stender, S., and D. B. Zilversmit. 1981. Transfer of plasma lipoprotein components and of plasma proteins into aortas of cholesterolfed rabbits. Arteriosclerosis. 1:38-49.

12. Morris, M. D., D. B. Zilversmit, and H. F. Hintz. 1972. Hyperlipoproteinemia in fasting ponies. J. Lipid Res. 13:383-389.

13. Folch, J., M. Lees, and G. H. Sloane Stanley. 1957. A simple method for the isolation and purification of total lipides from animal tissues. J. Biol. Chem. 226:497-509.

14. Stender, S., and S. Christensen. 1977. The concomitantly measured transfer of free cholesterol, esterified cholesterol, phospholipids and phosphoprotein from plasma into the aortic wall of stilboestroltreated cockerels. Atherosclerosis. 28:15-28.

15. Day, A. J., M. L. Wahlqvist, and D. J. Campbell. 1970. Differential uptake of cholesterol and different cholesterol esters by atherosclerotic intima in vivo and in vitro. Atherosclerosis. 11:301314.

16. Stender, S. 1979. Arterial entrance and metabolism of free and esterified plasma cholesterol measured in vivo in experimental animals by a dual isotope method. Atherosclerosis. 32:129-139.

17. Rose, H. G. 1967. In vitro precipitation of particulate radioisotopic cholesterol from human serum. Biochim. Biophys. Acta. 144:686689.

18. Rose, H. G. 1968. Studies on the equilibration of radioisotopic cholesterol with human serum lipoprotein cholesterol in vitro. Biochim. Biophys. Acta. 152:728-741.

19. Worm, A. M., E. Taaning, N. Rossing, H. H. Parving, and O. J. Clemmensen. 1981. Distribution and degradation of albumin in extensive skin disease. Br. J. Dermatol. 104:389-396.

20. Sodhi, H. S., and B. J. Kudchodkar. 1973. Labeling plasma lipoproteins with radioactive cholesterol. J. Med. Lab. Clin. Med. 82:111-124.

21. Davidson, N. O., E. H. Ahrens, Jr., H. L. Bradlow, D. J. McNamara, T. S. Parker, and P. Samuel. 1980. Unreliability of tritiated cholesterol: studies with $\left(1,2-{ }^{3} \mathrm{H}\right)$-cholesterol and $\left(24,25-{ }^{3} \mathrm{H}\right)$ cholesterol in humans. Proc. Natl. Acad. Sci. USA. 77:2255-2259.

22. Nicoll, A., R. Duffield, and B. Lewis. 1981. Flux of plasma lipoproteins into human arterial intima. Comparison between grossly normal and atheromatous intima. Atherosclerosis. 39:229-242.

23. Stender, S., S. Christensen, and O. Nyvad. 1978. Uptake of labelled free and esterified cholesterol from plasma by the aortic intimamedia tissue measured in vivo in three animal species. Atherosclerosis. 31:279-293.

24. Lin, D. S., W. E. Connor, R. W. Wissler, D. Vesselinovitch, and R. Hughes. 1980. A comparison of the turnover and metabolism of cholesterol in normal and atherosclerotic monkey aortas. J. Lipid Res. 21:192-201.

25. Schwartz, C. J., R. G. Gerrity, and L. J. Lewis. 1978. Arterial endothelial structure and function with particular reference to permeability. In Atherosclerosis Review 3. R. Paoletti and A. M. Gotto, editors. Raven Press, New York. 109-124.

26. Gerrity, R. G., H. K. Naito, M. Richardson, and C. J. Schwartz. 1979. Dietary induced atherogenesis in swine. Morphology of the intima in pre-lesion stages. Am. J. Pathol. 95:775-784.

27. Stein, Y., O. Stein, and G. Halperin. 1982. Use of ${ }^{3} \mathrm{H}-$ cholesteryl linoleyl ether for the quantitation of plasma cholesteryl ester influx into the aortic wall in hypercholesterolemic rabbits. Arteriosclerosis. 2:281-289. 